\title{
HUBUNGAN COPING STYLE DAN ANTICIPATORY GRIEF PADA ORANGTUA ANAK YANG DIDIAGNOSIS KANKER
}

\author{
Putri Lenggo Geni; Qisthi Rahmania \\ Psychology Department, Faculty of Humanities, BINUS University \\ Jln. Kemanggisan Ilir III No. 45, Kemanggisan-Palmerah, Jakarta Barat 11480 \\ pl.geni@yahoo.com
}

\begin{abstract}
Everyone copes with stressful events in his/her life differently. Three strategies in dealing with stress include problem-focused coping, emotion-focused coping, and religious-focused coping. Death of loved ones has been considered one of the major sources of stress in individuals and poses threat to their well being and adjustment if one's failed to cope with the grief. Interestingly, previous studies show that families and caregivers of terminally ill patients suffered bereavement prior to the actual death, a phenomenon labeled anticipatory grief. Article presents a study with the purpose to investigate the relationship between different coping styles and anticipatory grief in parents of children diagnosed with cancer. Fifty-five parents, ranging from 20 to 60-yearold, participated in this study. Results revealed that coping style, particularly emotion-focused coping, significantly predict anticipatory grief in parents of children diagnosed with cancer. However, both problemfocused coping and religious-focused coping did not predict parental anticipatory grief in this study.
\end{abstract}

Keywords: coping style, anticipatory grief, terminal illness, cancer

\begin{abstract}
ABSTRAK
Setiap orang memiliki cara yang berbeda dalam menghadapi masalah, tidak terkecuali ancaman kematian. Pada pasien penyakit kronis atau terminal seperti kanker, kematian anggota keluarga seakan-akan telah diantisipasi oleh anggota keluarga. Fenomena ini dikenal sebagai anticipatory grief yang tentunya ditangani secara berbeda dibandingkan dengan mereka yang kehilangan anggota keluarga secara tiba-tiba (sudden death). Terdapat tiga macam strategi dalam menghadapi permasalahan, yaitu problem-focused coping, emotion-focused coping, dan religious-focused coping yang masing-masing memiliki dampak berbeda terhadap masalah yang dialami. Artikel bertujuan untuk mengetahui kontribusi strategi coping terhadap anticipatory grief orangtua dari anak yang didiagnosis kanker. Sampel penelitian berjumlah 55 orangtua dari anak dengan diagnosis kanker yang dirawat di Rumah Sakit Kanker Dharmais Jakarta. Hasil penelitian menunjukkan bahwa emotional-focused coping memprediksi tingkat anticipatory grief pada orangtua, sedangkan problem-focused coping dan religious focused coping tidak memberikan kontribusi yang signifikan.
\end{abstract}

Kata kunci: coping style, anticipatory grief, penyakit kronis, kanker 


\section{PENDAHULUAN}

Kematian merupakan salah satu sumber stres utama dalam hidup. Penelitian oleh Holmes dan Rahe (1967) menempatkan kematian anggota keluarga pada posisi kelima dalam hal-hal yang menyebabkan stres. Hal yang serupa dikemukakan oleh Kane dan Oro (2007), yang menyatakan bahwa kehilangan pasangan atau anak merupakan peristiwa yang sangat menekan dan traumatis bagi keluarga yang ditinggalkan. Masih dari sumber yang sama, memiliki anggota keluarga yang menderita penyakit kronis (terminal) juga dapat menimbulkan trauma dan kedukaan yang mendalam khususnya bagi orangtua sebagai pengasuh utama karena kematian yang bersangkutan sering kali sudah diantisipasi (Kane \& Oro, 2007).

Penyakit kronis merupakan penyakit yang sulit atau bahkan tidak dapat disembuhkan. Salah satu yang termasuk penyakit kronis/terminal adalah kanker (Sarafino, 2008). Berdasarkan data WHO pada tahun 2008 kanker dinyatakan sebagai penyebab kematian nomor satu di dunia, tidak terkecuali anak-anak. Data registrasi kanker Rumah Sakit Kanker Dharmais pada tahun 2010, menunjukkan peningkatan jumlah pasien kanker pada anak dari tahun ke tahun.

Kanker yang diderita anak tentu memengaruhi hampir seluruh aspek terkait dalam kehidupannya, tidak terkecuali orangtua dan pengasuh (Kane \& Oro, 2007) baik secara psikologis, sosial, maupun finansial. Menurut Sarafino (2008), penderita penyakit kronis umumnya akan memerlukan pemeriksaan medis secara rutin. Tidak ada yang dapat memastikan apakah para penderita penyakit kronis akan pulih atau memburuk, namun kebanyakan orang akan menganggap bahwa vonis penyakit kronis (terminal) yang diberikan sebagai pertanda mendekatnya kematian (Burish et al, 1987 dalam Sarafino, 2008).

\section{Anticipatory Grief}

Pada kasus penyakit kronis dan terminal, gejala-gejala kedukaan dapat dialami sebelum kematian datang, dalam bentuk antisipasi atau yang sering disebut dengan anticipatory grief. Anticipatory grief merupakan sekumpulan set kognitif, reaksi afektif, budaya, dan sosial mengenai kematian yang dirasakan oleh pasien penyakit terminal dan keluarganya, sebelum kematian terjadi (Clayton dkk, 1973). Marwit \& Meuser (2004) membagi anticipatory grief ke dalam tiga dimensi, yaitu: (1) personal sacrifice burden merupakan dimensi yang menggambarkan pengorbanan seseorang, (2) heartfelt sadness \& longing merupakan dimensi yang menggambarkan kesedihan seseorang, dan (3) worry \& felt isolation merupakan dimensi yang menggambarkan kecemasan dan perasaan terisolasi.

Menurut Stroebe dan Schut (2001) anticipatory grief dapat berdampak terhadap kondisi fisik dan psikologis pasien maupun keluarganya. Beberapa penelitian menemukan bahwa anticipatory grief dapat membuat keluarga atau kerabat yang ditinggalkan beradaptasi secara lebih baik pascakematian karena sudah diantisipasi sebelumnya dibandingkan mereka yang ditinggalkan secara tiba-tiba (Gilliland \& Fleming, 1998). Walaupun demikian, anticipatory grief juga dapat berdampak negatif. Menurut Hillman (1997), diagnosis penyakit kronis pada anak dapat menimbulkan krisis emosional pada seluruh anggota keluarga. Di samping itu, cara keluarga menyikapi diagnosis yang diberikan juga dapat memengaruhi kesehatan anak. Spinetta, Rigler, \& Karon (1974) mengemukakan bahwa frekuensi, intensitas, dan kualitas interaksi antara orangtua dan anak yang didiagnosis dengan penyakit terminal cenderung menurun. Pola ini dimungkinkan sebagai salah satu penyebab munculnya perasaan terisolasi yang dialami pasien seiring dengan semakin lamanya penyakit tersebut diderita (Spinetta, Riegler, \& Karon, 1974). 


\section{Coping}

Penelitian menunjukkan bahwa keluarga dan pengasuh menunjukkan reaksi yang bervariasi terhadap diagnosis penyakit terminal khususnya kanker yang meliputi tidak percaya, shock, bingung hampa, cemas akan masa depan, marah, tegang, depresi, kecewa, bahkan penerimaan dan harapan (Grbich, Maddocks, \& Parker, 2001; Young, Dixon-Woods, Findlay, \& Heney, 2002). Di samping harus berusaha mengatasi reaksi emosional yang mereka alami, orangtua tetap harus merawat dan terus memberi dukungan terhadap anaknya. Oleh karena itu, peran coping menjadi sangat penting pada masa ini.

Coping didefinisikan sebagai upaya kognitif dan tindakan yang dilakukan individu untuk mengatasi masalah dan tuntutan yang dinilai merugikan atau melebihi kemampuan individu tersebut baik yang berasal dari dalam diri maupun lingkungan eksternal (Lazarus \& Folkman, 1984). Coping dapat dibagi berdasarkan tahapan-tahapan. Baker \& Chapmean, 1962 (dalam Lazarus \& Folkman, 1984) menguraikan tahapan dalam sebuah peristiwa yakni tahap anticipatory atau warning, tahap impact atau confrontation, dan tahap post-impact atau post-confrontation. Menurut Lazarus dan Folkman (1984), meskipun suatu peristiwa belum terjadi, isu-isu penting seperti apa, kapan, dan bagaimana peristiwa tersebut akan terjadi sudah dipertimbangkan pada tahap anticipatory (Lazarus \& Folkman, 1984). Antisipasi terhadap peristiwa yang belum terjadi ini dinyatakan juga berpengaruh terhadap tingkat stres dan strategi coping seseorang (Folkins, 1970; Monat, Averill, \& Lazarus, 1972; dan Monat, 1976 dalam Lazarus \& Folkman, 1984).

Lazarus \& Folkman (1984) membagi strategi coping menjadi dua berdasarkan tujuannya, yaitu problem-focused coping dan emotion-focused coping. Problem-focused coping meliputi usahausaha untuk memecahkan masalah yang ditujukan langsung pada penyebab stres atau melakukan sesuatu untuk mengubah dan mengatasi stres tersebut seperti melakukan perencanaan. Coping ini umumnya dipergunakan oleh individu dalam menghadapi masalah atau situasi yang dianggap dapat dikontrol atau dikuasainya. Sedangkan emotion-focused coping adalah suatu usaha untuk mengatasi atau mengurangi ketegangan emosional yang timbul akibat sumber stres yang dihadapi misalnya mencari dukungan emosional dari orang-orang terdekat dan mencari sisi positif dari masalah yang dihadapi (Carver, Scheier, \& Wintraub, 1989).

Pargament (1997) menambahkan salah satu jenis coping yang diberi nama religious coping yang berfokus pada cara seseorang mengatasi masalah dengan meningkatkan intensitas ibadah karena percaya kepada Tuhan dapat membantu menyelesaikan masalah yang sedang dihadapi. Strategi ini adalah strategi coping yang paling banyak digunakan oleh orang Indonesia (Dahlan, 2005). Penelitian menunjukkan bahwa kebanyakan orang akan menggunakan religious coping apabila situasi yang dihadapi merupakan suatu hal yang stressful dan negatif seperti kematian, penyakit, perceraian atau perpisahan dengan pasangan karena masalah hukum (Pargament, 1997).

Beberapa penelitian telah mengidentifikasi upaya yang dilakukan oleh seseorang untuk mengatasi masalah atau reaksi emosional yang ditimbulkan ketika anggota keluarganya didiagnosis menderita penyakit terminal. Mayer (2001) mengidentifikasi beberapa pendekatan coping di antaranya penyangkalan, marah, putus asa, dan pengabaian. Di samping itu, beberapa upaya coping yang lebih positif juga terlihat contohnya merasionalisasi mengenai keadaan pasien (Hull, 1992), berpikir positif dan mencari kesibukan (Martens \& Davies, 1990), berolahraga, hingga relaksasi (Grbich, Maddocks, \& Parker, 2001). Menurut Zarit (1982, dalam Lane, 2005) strategi coping yang digunakan oleh keluarga dapat berubah sepanjang masa anticipatory grief.

Al-Gamal dan Long (2010) menuturkan bahwa strategi coping yang dilakukan oleh orangtua dan keluarga pasien dapat berdampak besar pada kondisi psikologis, fisiologis, maupun kualitas hidup pasien dan keluarganya. Overholser dan Friz (1990 dalam Gamal \& Long, 2010) juga merekomendasikan kepada tenaga medis untuk membekali orangtua dengan strategi coping yang 
adaptif. Meskipun demikian, hingga saat ini penelitian yang menghubungkan antara penggunaan strategi coping dan anticipatory grief masih terbatas. Oleh karena itu, studi ini diharapkan dapat berkontribusi dengan menelaah hubungan antara strategi coping dan anticipatory grief.

Berdasarkan studi literatur, strategi coping yang terdiri dari problem-focused, emotionfocused, dan religious-focused memprediksi anticipatory grief pada orangtua. Lebih tepatnya, ketiga strategi coping berkorelasi secara negatif terhadap gejala anticipatory grief. Jadi, semakin efektif strategi coping yang digunakan oleh orangtua, tingkat anticipatory grief akan semakin menurun. Kontribusi masing-masing strategi coping terhadap anticipatory grief akan dianalisis secara terpisah.

\section{METODE PENELITIAN}

Partisipan dalam penelitian ini adalah 55 orangtua dari anak dengan diagnosis kanker di ruang rawat inap Rumah Sakit Kanker Dharmais $(M$ usia $=36.35, S D=6.971)$. Partisipan terdiri dari 41 wanita $(74,5 \%)$ dan 14 pria $(25,5 \%)$. Tingkat pendidikan partisipan penelitian cukup bervariasi, yaitu lulusan SD sebanyak 6 orang, sekolah menengah sebanyak 35 orang, dan pendidikan lanjutan sebanyak 12 orang.

Berdasarkan lama diagnosis, mayoritas partisipan telah mengetahui diagnosis kanker terhadap anaknya antara $0-6$ bulan yaitu sebanyak 23 orang (41,8\%), kemudian selama 6-12 bulan sebanyak 13 subjek (23,6\%), selama 12-24 bulan sebanyak 15 subjek (27,3\%), dan sebanyak 2 subjek (3,6\%) yang telah mengetahui diagnosis anaknya selama lebih dari 24 bulan. Lamanya diagnosis akan dijadikan sebagai kontrol dengan pertimbangan adanya perubahan dalam strategi coping yang digunakan partisipan selama masa anticipatory grief (Zarit, 1982 dalam Lane, 2005).

\section{Pengukuran}

Anticipatory grief pada penelitian ini diukur dengan menggunakan alat ukur yang telah diadaptasi dari Marwitt-Meuser Caregiver Grief Inventory (short-form). Kuesioner ini terdiri dari 18 pernyataan yang dapat mewakili perasaan berduka pada orangtua yang memiliki anak dengan diagnosis kanker. Partisipan memberikan respons terhadap pernyataan tersebut dalam skala Likert ( angat tidak setuju $=1$, tidak setuju $=2$, agak setuju $=3$, setuju $=4$, sangat setuju $=5$ ). Seperti halnya inventory oleh Marwitt-Meuser, kuesioner ini terdiri dari 3 dimensi yaitu personal sacrifice burden $(\alpha=.83)$, heartfelt sadness and longing $(\alpha=.80)$, dan worry and felt isolation $(\alpha=.80)$. Ketiga dimensi tersebut dapat dijadikan satu skor total $(\alpha=.90)$ yang menggambarkan anticipatory grief seseorang. Alat ukur ini memiliki internal consistency yang cukup tinggi dengan cronbach's alpha .84.

Alat ukur Ways of Coping merupakan alat ukur yang dikembangkan oleh Lazarus dan Folkman. Alat ukur ini kemudian direvisi oleh Vitaliano, Russo, Carr, Maiuro, dan Becker lalu diadaptasi oleh Dahlan ke versi bahasa Indonesia. Reliabilitas dan validitas untuk masing-masing variabel telah diuji oleh Dahlan (2005) pada sampel karyawan dengan hasil problem-focused coping $(\alpha=.81)$, emotion-foused coping $(\alpha=.81)$. Dahlan (2005) juga menambahkan dimensi religiousfocused coping $(\alpha=.91)$ yang diambil dari teori Pargament (1997), kemudian dibuat item-item pertanyaanya oleh Dahlan (2005).

Kuesioner Ways of Coping Checklist menggunakan skala likert 1-5. Skala 1 mewakili jawaban "tidak relevan untuk dilakukan dalam mengatasi situasi stres yang saya hadapi". Skala 2 mewakili jawaban "relevan, tapi tidak saya lakukan dalam mengatasi situasi stres yang saya hadapi". Skala 3 hingga 5 berturut-turut mewakili jawaban "jarang", "sering" dan "selalu" dilakukan untuk mengatasi stres yang dihadapi oleh subjek. 
Partisipan merupakan orangtua yang sedang mengunjungi pasien di instalasi rawat inap Rumah Sakit Dharmais Jakarta. Proses pengambilan data dilakukan selama dua hingga mencapai jumlah 55 orang. Partisipan diminta untuk mengisi kuesioner Ways of Coping Checklist dan MarwittMeuser Caregiver Grief Inventory (short-form) pada saat yang bersamaan.

\section{HASIL DAN PEMBAHASAN}

Data deskriptif dan korelasi antar variabel penelitian dirangkum dalam tabel 1. Terdapat korelasi yang signifikan antara skor anticipatory grief $(M=51.90, S D=11.31)$ dan emotion-focused coping $(M=34.36, S D=7.66), r=.35, p<.05$, serta anticipatory grief dan religious-focused coping $(M=22.08, S D=4.78), r=.29, p<.05$. Kemudian, tidak ditemukan korelasi signifikan antara anticipatory grief dan problem-focused coping $(M=22.41, S D=4.88), r=.18$, ns. Jadi, orangtua yang mengalami anticipatory grief yang tinggi juga melakukan lebih banyak strategi coping emosional dan religius.

Analisis multiple regression dilakukan dengan anticipatory grief sebagai kriterion dan lama diagnosis dan ketiga strategi coping sebagai prediktor. Hasil analisis menunjukkan bahwa keempat prediktor menjelaskan $25 \%$ variasi dari anticipatory grief $(R=.498), F(4,46)=2.97, p<.05$. Lama diagnosis tidak memprediksi AG secara signifikan $\mathrm{F}(1,49)=2.49$, $n s$, dan hanya menjelaskan variasi pada AG sebesar $6 \%$.

Ketiga strategi coping secara simultan memprediksi $19 \%$ dari variasi pada anticipatory grief $F$ $(1,46)=3.00, p>.05$. Kemudian, stadardized regression coefficient menunjukkan emotion-focused coping merupakan satu-satunya strategi coping yang secara signifikan memprediksi anticipatory grief, $b=.29, t(51)=1.96, p<.05$. Hal ini menunjukkan bahwa tingginya emotion-focused coping diasosiasikan dengan meningkatkan anticipatory grief pada orangtua pasien.

Tabel 1 Korelasi antar-Variabel Penelitian

\begin{tabular}{lccccc}
\hline & Diagnosis & AG & PFC & EFC & RFC \\
\hline Lama diagnosis & - & -.282 & -.046 & .001 & .048 \\
Anticipatory grief & -.282 & - & .176 & $.347^{*}$ & $.289^{*}$ \\
Problem-focused coping & -.046 & .176 & - & -.124 & .254 \\
Emotion-focused coping & .001 & $.347^{*}$ & -.124 & - & .100 \\
Religious-focused coping & .048 & $.289^{*}$ & .254 & .100 & - \\
\hline
\end{tabular}

* Signifikan pada level $p<.05$

Penelitian terdahulu telah menunjukkan pentingnya mengidentifikasi antocipatory grief dan faktor terkait yang berpengaruh terhadap penyesuaian diri dan kualitas hidup pasien penyakit terminal. Artikel bertujuan untuk meneliti hubungan antara strategi coping dan anticipatory grief pada orangtua dari anak yang diagnosis memiliki kanker. Strategi coping diharapkan memprediksi anticipatory grief pada orangtua secara signifikan setelah mengontrol jangka waktu sejak anak mereka didiagnosis memiliki kanker. Sesuai dengan hipotesis yang telah dirumuskan, hasil penelitian menunjukkan bahwa strategi coping memprediksi tingkat anticipatory grief pada orangtua secara signifikan. Hal ini sejalan dengan penelitian sebelumnya yang mengasosiasikan anticipatory grief dengan beragam strategi coping (Grbich, Parker, \& Maddocks, 2001; Martens \& Davies, 1990; Mayer, 2001). 
Ketika dianalisis secara terpisah untuk melihat kontribusi masing-masing strategi coping, hanya emotion-focused coping yang secara signifikan memprediksi variasi pada anticipatory grief, sedangkan problem-focused coping dan religious-focused coping tidak memberikan kontribusi yang signifikan. Dengan demikian, hanya sebagian dari hipotesis penelitian yang didukung oleh hasil tersebut. Tidak signifikannya kontribusi dari problem-focused coping dan religious-focused coping dimungkinkan karena adanya faktor lain yang memoderasi hubungan antara kedua variabel ini seperti attachment antara orang tua dan anak (Stroebe, 2002) dan tingkat stres yang dialami oleh orangtua baik yang terkait dengan kondisi anak maupun situasi lainnya. Faktor ini tidak diikutsertakan dalam penelitian dan diharapkan dapat ditelaah lebih jauh pada penelitian berikut.

Selanjutnya, bertentangan dengan prediksi bahwa strategi coping berkorelasi secara negatif terhadap anticipatory grief, hasil penelitian justru menunjukkan sebaliknya yaitu semakin tinggi emotion-focused coping diasosiasikan dengan meningkatnya anticipatory grief pada orangtua pasien. Walaupun demikian, hasil tersebut perlu diinterpretasi secara hati-hati karena alat ukur coping yang digunakan dalam penelitian tidak membedakan antara metode spesifik masing-masing strategi coping. Contohnya, emotion-focused coping dapat berupa mencari sisi positif dari situasi yang dialami (positive reinterpretation) maupun penyangkalan (denial) (Carver, Scheier, Wintraub, 1989). Hal ini tentunya dapat memberikan dampak yang berbeda terhadap stres atau anticipatory grief yang dialami orangtua (Lane, 2005). Namun pada alat ukur yang berbentuk short-form, meskipun terbukti sahih dan akurat, metode spesifik pada masing-masing strategi coping ini hanya diwakili oleh sedikit item sehingga kurang dapat menggambarkan coping secara mendetail. Untuk penelitian lanjutan, hal ini dapat diatasi dengan menggunakan alat ukur yang lebih sensitif atau menggali informasi tambahan secara kualitatif dengan metode campuran (mixed method).

\section{SIMPULAN}

Selain beberapa keterbatasan yang telah diuraikan, penelitian ini juga menggunakan partisipan yang terbatas dan dimungkinkan memengaruhi temuan tersebut. Walaupun demikian, hasil penelitian ini diharapkan dapat membangkitkan minat, menambah informasi mengenai hubungan antara strategi coping dan anticipatory grief dan dapat bermanfaat baik secara teoretis maupun praktis sebagai pertimbangan dalam intervensi tenaga medis terhadap keluarga pasien penyakit terminal. Berkaitan dengan penelitian yang akan datang, jumlah partisipan yang lebih besar dan beragam dalam latar belakang diharapkan dapat memberikan gambaran yang lebih akurat dan dapat digeneralisasi dalam menjelaskan hubungan antara strategi coping dan anticipatory grief. Studi longitudinal juga dapat dilakukan untuk menginvestigasi perubahan dalam strategi coping dalam hubungannya dengan anticipatory grief yang dialami orangtua.

\section{DAFTAR PUSTAKA}

Al-Gamal \& Long. (2010). Anticipatory Grieving among Parents Living with a Child with Cancer. Journal of Advanced Nursing 66, 1980-1990.

Carver, C. S., Scheier, M. F., \& Weintraub, J. K. (1989). Assessing Coping Strategies: A Theoretically Based Approach. Journal of Personality and Social Psychology, 56, 267-283.

Dahlan, W. (2005). Model Proses Stres dengan Tiga Strategi Coping. Disertasi Doktoral yang tidak dipublikasikan. Depok: Fakultas Psikologi Universita Indonesia. 
Gilliland, G., \& Fleming, S. (1998). A Comparison of Spousal Anticipatory Grief and Conventional Grief. Death Studies, 22, 541-570.

Grbich, C., Parker, D., \& Maddocks, I. (2001). The Emotions and Coping Strategies of Caregivers of Family Members with Terminal Cancer. Journal of Palliative Care, 17, 30-36.

Hillman, K. A. (1997). Comparing Child-Rearing Practices in Parents of Children with Cancer and Parents of Healthy Children. Journal of Pediatric Oncology Nursing 14, 53-67.

Hull, M. (1992). Coping Strategies of Family Caregivers in Hospice Homecare. Oncology Nursing Forum, 19, 1170-1187.

Lane, B. N. (2005). Understanding Anticipatory Grief: Relationship to Coping Style, Attachment Style, Caregiver Strain, Gender Role, Identification, and Spirituality. Disertasi Doktoral yang tidak dipublikasikan. TX: Texas A\&M University.

Lazarus, R. S., \& Folkman, S. (1984). Stres, Appraisal, and Coping. New York, NY: Springer.

Martens, N. \& Davies, B. (1990). The Work of Patients and Spouses in Managing Advanced Cancer at Home. Hospice Journal, 6, 55-73.

Mayer, M. (2001). Chronic Sorrow in Caregiving Spouses of Patients with Alzheimer's Disease. Journal of Aging and Identity, 6, 49-60.

Meuser, T. M., Marwit, S. J., \& Sanders, S. (2004). Marwitt-Meuser Caregiver Grief Inventory (short form). Dibuka pada 27 Oktober 2010 dari: http://alzheimer.wustl.edu/About_Us/PDFs/ Caregiver_Grief_Inventory_SF.pdf

Pargament, K. (1997). The Psychology of Religion and Coping: Theory, Research, and Practice. New York: The Guilford Press.

Sarafino, E. P. (2008). Health Psychology: Biopsychosocial Interaction ( $6^{\text {th }}$ ed.). New Jersey: John Wiley \& Sons, Inc.

Spinetta, J.J., Rigler, D. \& Karon, M. (1974). Personal Space as a Measure af a Dying Child's Sense of Isolation. Journal of Consulting and Clinical Psychology, 42, 751-756.

Stroebe, M. \& Schut, H. (2001). Models of Coping with Bereavement: a Review. In M. S. Stroebe, R. O., Hansson, W. Stroebe, \& H. Schut (Eds.), Handbook of bereavement research (pp. 375403). Washington, DC: American Psychological Association.

Stroebe, M. (2002). Paving the Way: from Early Attachment Theory to Contemporary Bereavement Research. Mortality, 7, 127-138.

Young, B., Dixon-Woods, M., Findlay, M. \& Heney, D. (2002). Parenting in a Crisis: Conceptualizing Mothers of Children with Cancer. Social Science and Medicine 55, 1835 1847. 